\title{
Impacto do marketing dos processos de divulgação nas doações de córneas a um banco de tecidos oculares humanos e avaliação do perfil socioeconômico de seus doadores
}

\author{
Marketing role of corneal graft tissue donation to an eye bank and donors' \\ socioeconomic profile
}

Roberta Jansen de Mello Farias ${ }^{1}$
Luciene Barbosa de Sousa

Trabalho realizado no Hospital Oftalmológico de Sorocaba - Sorocaba (SP) - Brasil.

${ }^{1}$ Pós-graduanda da Universidade Federal de São Paulo UNIFESP - São Paulo (SP) - Brasil.

${ }^{2}$ Oftalmologista e Chefe do Serviço de Residência do Hospital Oftalmológico de Sorocaba - Sorocaba (SP) Brasil.

Endereço para correspondência: Rua Mairinque, 261/ 152 - São Paulo (SP) CEP 04037-020

E-mail: robertafarias@bol.com.br

Recebido para publicação em 28.11.2005

Última versão recebida em 26.09.2007

Aprovação em 01.10 .2007

\begin{tabular}{|c|}
\hline RESUMO \\
\hline 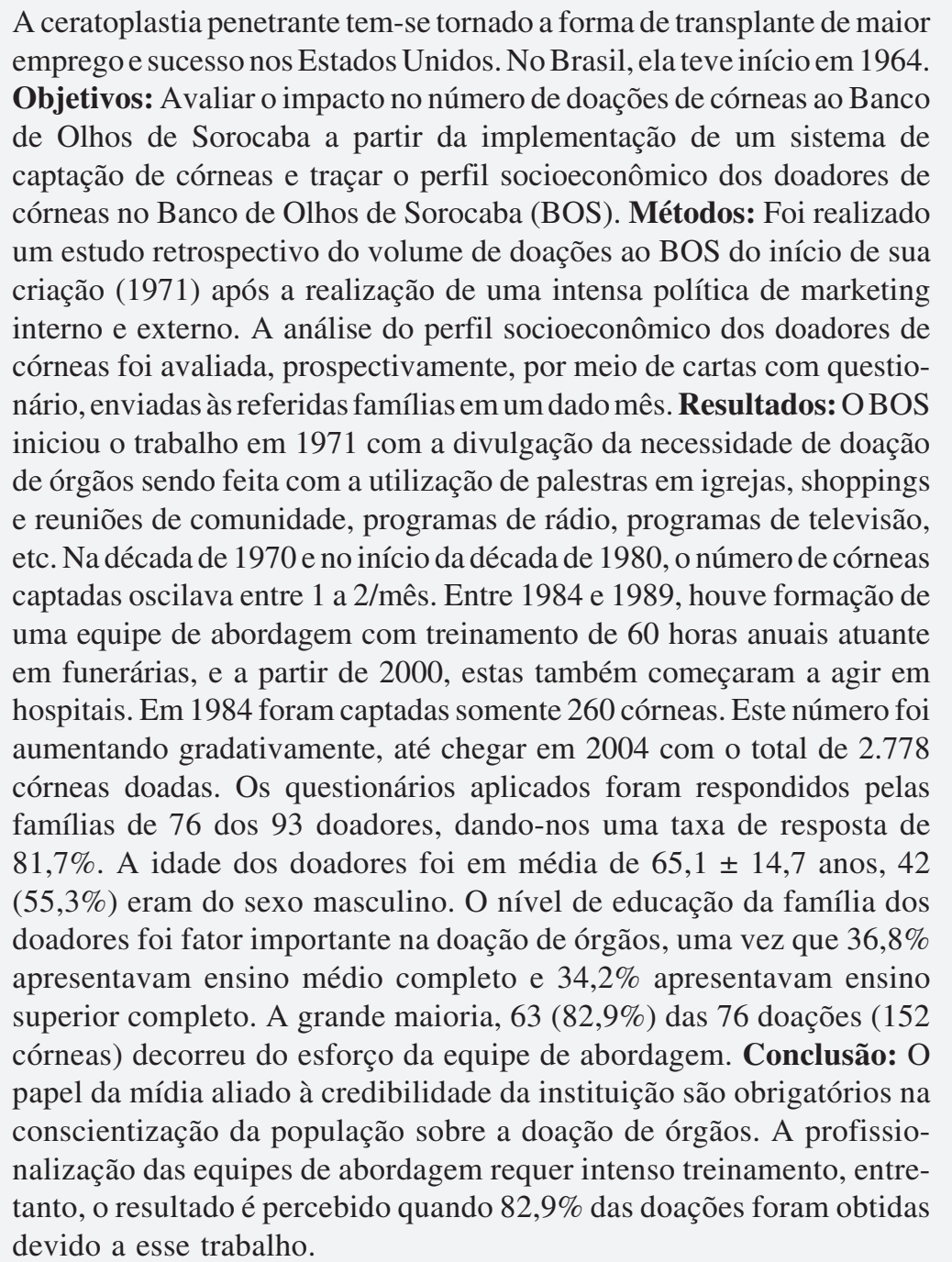 \\
\hline
\end{tabular}

Descritores: Banco de olhos; Doação dirigida de tecido; Doadores de tecidos; Obtenção de tecidos e órgãos/métodos; Córnea; Classe social; Marketing 


\section{INTRODUÇÃO}

A ceratoplastia penetrante tem-se tornado a forma de transplante de maior emprego ${ }^{(1)}$ e sucesso nos Estados Unidos, com 35.930 córneas transplantadas em 1987(2). Em 1985, nos Estados Unidos existia uma deficiência em torno de 3.500 a 5.000 córneas $^{(3)}$. Na cidade de Nova York, 350 pacientes aguardavam em média 3 meses por um transplante de córnea ${ }^{(4)}$.

Em 1996, 2.645 transplantes de córnea (43 por milhão) foram realizados no Reino Unido e Irlanda e 2.035 (53 por milhão) na Espanha. Ao final de 1996, 2.017 pacientes (52,5 por milhão) estavam registrados na fila de espera na Espanha e 437 (7 por milhão) no Reino Unido e Irlanda ${ }^{(5-6)}$. No Brasil, em abril de 2004 havia 22.871 pessoas inscritas na fila de transplante de córnea ${ }^{(1)}$.

Em função da grande lista de espera para transplantes de córnea, especial atenção tem sido dada pelo Ministério da Saúde à implantação de Bancos de Tecidos Oculares. Assim, foi instituído em setembro de 2001, o Programa Nacional de Implantação de Bancos de Tecidos Oculares, que objetivava gerar as condições necessárias para a implantação de 30 bancos de tecidos oculares distribuídos em todo o país. A meta seria ampliar a captação de córneas para fins de transplante, encurtar o tempo de espera em fila e aumentar significativamente (multiplicar por quatro nos próximos três anos) o número de transplantes de córnea realizados no Brasil ${ }^{(1)}$.

Se considerarmos a atual capacidade de captação de córnea no Brasil e a realização, em média, de 2,5 mil transplantes de córneas por ano, esta fila só seria resolvida em sete anos (sem contar o aumento de casos neste período) ${ }^{(1)}$.

Os recursos destinados à implantação do Programa foram da ordem de $\mathrm{R} \$ 1.547 .400,00$ para compra de equipamentos básicos para o funcionamento de Banco de tecidos oculares ${ }^{(1)}$.

$\mathrm{O}$ incentivo financeiro do governo federal foi decisivo para a criação dos Bancos de tecidos oculares, entretanto, é necessário que os mesmos consigam desenvolver políticas internas e externas capazes de incentivar a doação de córneas.

\section{OBJETIVOS}

Avaliar o impacto no número de doações de córneas ao Banco de Olhos de Sorocaba (BOS) a partir da implementação de um sistema de captação de córneas e traçar o perfil socioeconômico dos doadores de córneas no Banco de Olhos de Sorocaba (BOS).

\section{Metodologia}

Foi realizado um estudo retrospectivo do volume de doações ao Banco de Olhos de Sorocaba (BOS) do início de sua criação (1971) e após a realização de uma intensa política de marketing interno e externo. A análise do perfil socioeconômico dos doadores de córneas foi avaliada, prospectivamente, por meio de cartas com questionário, enviadas às referidas famílias em um dado mês.
O questionário, a ser respondido pela família dos doadores, foi enviado por correio 15 dias após o falecimento do doador e constava das seguintes questões sobre o doador: sexo e idade; causa da morte (respiratória, cardiológica, acidente vascular cerebral, infecciosa, acidental, tumoral ou por homicídio); tipo de doação (se foi assinada previamente ou efetuada após a abordagem da equipe de transplantes); religião (católico, protestante, evangélico, testemunha de Jeová ou outro); grau de instrução (analfabeto, ensino fundamental completo ou incompleto, ensino médio completo ou incompleto, superior completo ou incompleto); renda mensal (<1 salário mínimo (SM), 1 a 2 SM, 2 a 3 SM, 3 a 5 SM, 5 a $10 \mathrm{SM}, 10$ a $20 \mathrm{SM},>20 \mathrm{SM}$ ou sem rendimento) e existência de algum caso de cegueira ou necessidade de transplante na família.

Sobre a pessoa que assinou a doação, questionou-se sobre: religião (católico, protestante, evangélico, testemunha de Jeová ou outro); grau de instrução (analfabeto, ensino fundamental completo ou incompleto, ensino médio completo ou incompleto, superior incompleto ou superior completo); renda mensal (<1 salário mínimo $(\mathrm{SM}), 1$ a $2 \mathrm{SM}, 2$ a $3 \mathrm{SM}, 3$ a 5 SM, 5 a 10 SM, 10 a 20 SM, > 20 SM ou sem rendimento); existência de algum caso de cegueira ou necessidade de transplante na família.

Análise da política de divulgação externa, desenvolvida no BOS desde 1971 até a atualmente realizada, e a reflexão no número de doações de córneas foram avaliadas utilizando-se relatórios mensais e marcas históricas apresentados à diretoria do BOS.

\section{RESULTADOS}

O BOS iniciou o seu trabalho em 1971, auxiliado pela implantação de um setor de marketing, cujo trabalho é financiado pelo próprio Banco de olhos e pela ajuda de parcerias com a maçonaria, jornais e rádios. As ações desenvolvidas foram:

- palestras em indústrias nas semanas de prevenção de acidentes, em que se mostrou não só a importância do uso de equipamentos de proteção para a prevenção de acidentes, como os danos oculares que podem ocorrer e, finalmente, a necessidade de doação de córneas;

- sermões de padres, pastores e reverendos para expor a importância de ajudar o próximo, mesmo após a morte. No caso dos espíritas foi preciso superar o mito da reencarnação;

- programas de rádio fizeram entrevistas com os voluntários do Banco de Olhos;

- jornais publicaram anúncios para incentivar as doações e, ao mesmo tempo, anúncios agradecendo o doador e seus familiares pelas córneas doadas; publicaram ainda notas referentes à missa de $7^{\circ}$ dia do doador;

- festas tradicionais da cidade, como: Feira da Agricultura, Pecuária e Indústria de Sorocaba; Semana do Tropeiro e Festa Junina foram utilizadas para arrecadar fundos para o Banco de Olhos; 
- feiras de saúde: exposição de um estande do Banco de Olhos para informações sobre doações;

- propagandas de televisão com artistas famosos;

- adesivos para carros e propaganda em telas de cinemas incentivando a doação;

- propagandas ilustrativas do BOS em painéis no fundo de ônibus;

- divulgação de atividades em jornais da cidade;

- painéis em funerárias e

- palestras em shoppings, hipermercados e comunidades de bairro.

Os resultados do marketing externo começaram a aparecer aos poucos. Na década de 70 e no início da década de 80 , o número de córneas captadas oscilava entre 1 a 2/mês. Em 1984 foram captadas somente 260 córneas. Este número foi aumentando gradativamente, até chegar em 2004 no total de 2.778 córneas doadas, como mostra o gráfico a seguir. De 01/01/2005 a 31/05/2005, foram captadas 3.684 córneas.

Entre 1984 e 1999, as abordagens eram feitas somente em funerárias, onde os próprios funcionários, que haviam recebido treinamento para abordagem pelo BOS, abordavam a família do falecido e, no caso de uma resposta positiva, acionavam o técnico de captação de plantão no BOS.

A partir de 2000, as abordagens começaram a ocorrer também nos hospitais, sendo o treinamento das equipes de abordagens o principal fator indicador do aumento do número de doações ao Banco de Olhos de Sorocaba.

Existem hoje sete equipes de abordagens treinadas para a captação de córneas para o Banco de Olhos de Sorocaba, que se encontram nos seguintes hospitais públicos: Hospital Regional de Sorocaba, Santa Casa de Sorocaba, Hospital Sanatorinhos de Itu, Santa Casa de Salto, Hospital Regional de Itapetininga e Funerária de Tatuí. No Hospital da Unimed em Sorocaba, não há equipe treinada pelo BOS, mas a própria equipe de enfermagem do Hospital é responsável pela abordagem.

Cada equipe é constituída de quatro técnicos de enfermagem que se revezam em turnos de 12 horas e receberam treinamentos teóricos e curso de reciclagem com embasamento em leis, anatomia ocular e processo de abordagem da família num total de $60 \mathrm{~h}$ anuais de carga horária, tornando-se capacitados para abordar, captar e preservar globos oculares. A idéia central seria abordar todos os casos, visando à conscientização da população e da própria equipe sobre a importância do ato de doar.

Como para o BOS toda pessoa é considerada um doador em potencial, o limite mínimo é de dois anos de idade, e não há limite máximo, logo não existe recusa à doação, e a equipe de abordagem tenta entrevistar os familiares de todos os falecidos. Depois da captação do globo, são realizados os testes sorológicos e a análise de viabilidade do tecido. As equipes de abordagens foram responsáveis por um aumento no número de doações de 668, em 1999, para 1.593, em 2001, quando os grupos de trabalho estavam efetivamente organizados.

No mês de maio de 2004, quando foi aplicado o questionário, foram recebidas 185 doações referentes a 93 óbitos. $\mathrm{O}$ questionário aplicado foi respondido pelas famílias de 76 dos 93 doadores, dando-nos uma taxa de resposta de $81,7 \%$.

A idade dos doadores foi em média de $65 \pm 14,7$ anos, $42(55,3 \%)$ eram do sexo masculino e a grande maioria,

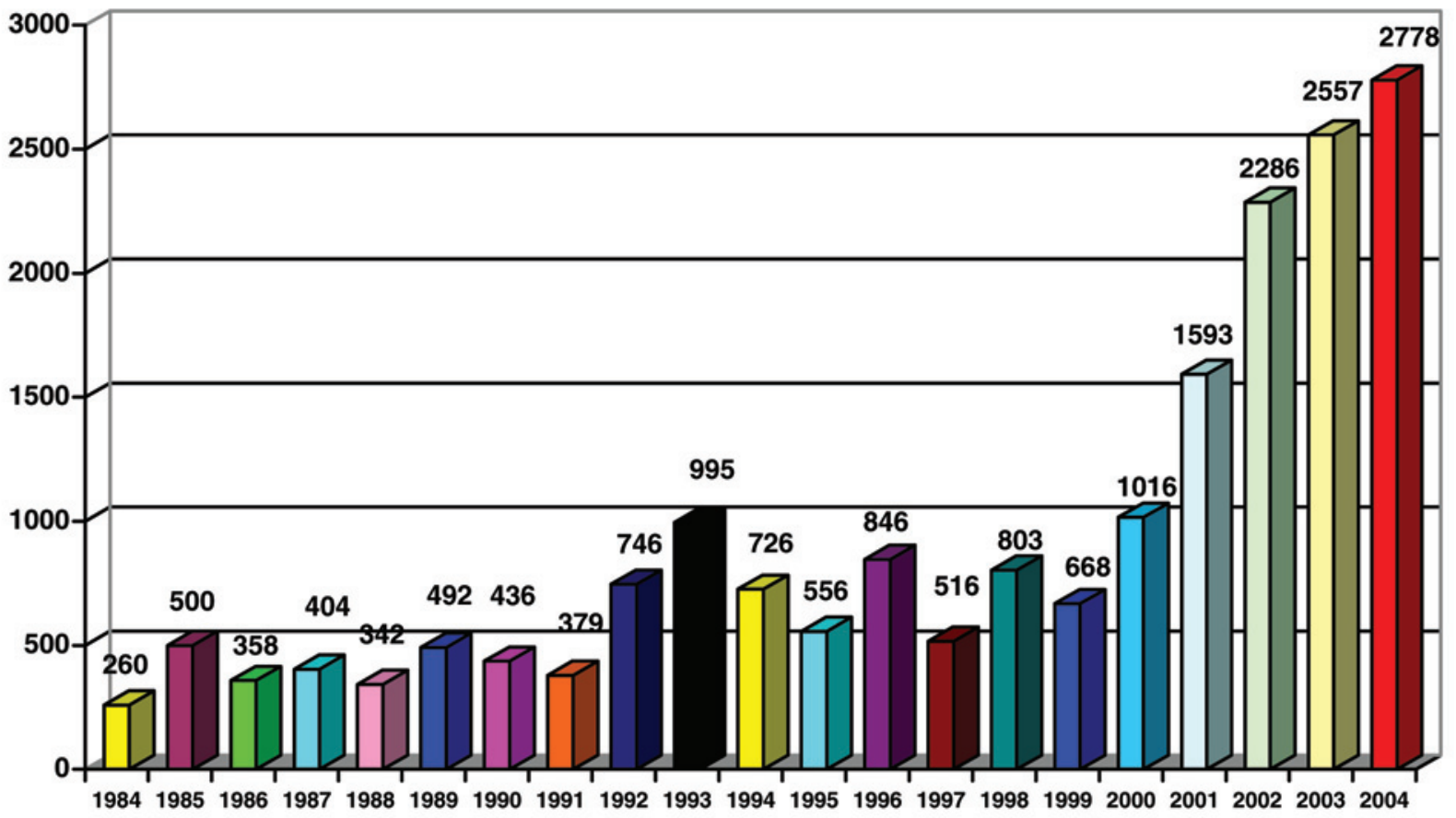

Gráfico 1 - Doações de tecidos oculares entre 1984 e 2004 
$63(82,9 \%)$ das córneas doadas decorreu do esforço da equipe de abordagem, como mostra a tabela 1 .

$\mathrm{Na}$ tabela 2 encontram-se dados referentes à caracterização sociocultural dos doadores. Sessenta e um $(80,3 \%)$ dos 76 doadores eram católicos. Quarenta e cinco $(59,2 \%)$ possuíam apenas o ensino fundamental completo ou incompleto contra apenas $3(3,9 \%)$ que apresentavam ensino superior completo. Sessenta e quatro $(84,2 \%)$ dos 76 doadores não apresentaram casos na família de alguém que tivesse ficado cego ou que tivesse necessitado de transplante.

Sobre a caracterização das pessoas que assinaram a carta de doação: $60(78,9 \%)$ eram católicos, enquanto $14(18,4 \%)$ eram evangélicos, $28(36,8 \%)$ apresentavam ensino médio completo e $26(34,2 \%)$ apresentavam ensino superior completo. Das 76 pessoas que assinaram a carta de doação, 60 $(78,9 \%)$, não apresentavam caso de cegueira ou de pessoa necessitando de transplante, na família.

\section{DISCUSSÃO}

Não há dúvidas de que a deficiência universal de doadores de órgãos é o obstáculo mais importante na provisão de transplantes a diversos pacientes. Parece que a deficiência de doadores de órgãos não é primariamente o resultado da falta de doadores, mas consequiência da dificuldade de identificálos, obter o consentimento da família e captar os órgãos e/ou tecidos $^{(7)}$.

Foram apontadas inúmeras razões pelas quais córneas não são captadas para doações, tais como: contra-indicações médicas, oposição da família durante a abordagem ou puramente problemas logísticos ${ }^{(8)}$. Os problemas logísticos mais apon-

Tabela 1. Distribuição da doação de tecido ocular quanto ao tipo de abordagem

\begin{tabular}{|c|c|c|}
\hline \multirow{3}{*}{ Tipo de Doação Questão 4} & \multicolumn{2}{|c|}{$n=76$} \\
\hline & $\mathbf{n}$ & $(\%)$ \\
\hline & 13 & $(17,1)$ \\
\hline Abordagem da equipe de transplantes & 63 & $(82,9)$ \\
\hline
\end{tabular}

\begin{tabular}{|c|c|c|}
\hline $\begin{array}{l}\text { Questões } \\
\text { Reliqião }\end{array}$ & \multicolumn{2}{|c|}{$\mathrm{n}=76$} \\
\hline Questão 5 & $\mathbf{n}$ & $(\%)$ \\
\hline Católico & 61 & $(80,3)$ \\
\hline Evangélico & 15 & $(19,7)$ \\
\hline Grau de Instrução & & \\
\hline Analfabeto & 12 & $(15,8)$ \\
\hline Ensino fundamental completo ou incompleto & 45 & $(59,2)$ \\
\hline Ensino médio completo ou incompleto & 13 & $(17,1)$ \\
\hline Superior incompleto & 3 & $(3,9)$ \\
\hline Superior completo & 3 & $(3,9)$ \\
\hline Caso na família & & \\
\hline Sim & 12 & $(15,8)$ \\
\hline Não & 64 & $(84,2)$ \\
\hline
\end{tabular}

tados são: remoção do corpo antes da abordagem, serviço funerário impedindo a ação da equipe, indisponibilidade de sala de captação devido à autópsia, indisponibilidade da equipe de abordagem e finalmente a incapacidade em contactar os familiares $^{(8-9)}$.

Sem o suporte da população geral e sua vontade para doar não haveria órgãos para transplantar. Deve ficar claro, entretanto, que o canal mais adequado para atingir a opinião pública é a mídia. Encontros periódicos com jornalistas e líderes de opinião em transplantes consistem em abordagens pragmáticas para influenciar e educar a mídia em assuntos relacionados a transplantes. Idéias errôneas devem ser discutidas abertamente e, ao mesmo tempo, enfatizados os aspectos positivos de salvar vidas por meio da doação de órgãos e transplantes ${ }^{(10)}$.

O BOS tendo como mercado-alvo toda a população de Sorocaba, exceto crianças menores de dois anos, adotou o que se chama de "marketing responsável", em que o foco é a necessidade do maior número de doações de córneas e não a diferença, ou seja, a pré-seleção de doadores. A imagem é trabalhada no dia-a-dia, de tal forma que a população tenha confiança no seu trabalho. Por intermédio de intensas campanhas de doação e da educação da população sorocabana sobre doação de órgãos e, principalmente, da ação efetiva das equipes de abordagem, o BOS conseguiu um salto na captação de córneas de 260 córneas doadas em 1984 para 2.778 em 2004, o que representou um aumento de aproximadamente 968\% no número de doações em 20 anos.

As equipes de abordagem do BOS começaram a ser montadas em 2000. Em 2001, elas estavam efetivamente instaladas em dois hospitais públicos principais da região: a Santa Casa de Sorocaba e o Hospital Regional de Sorocaba, que apresentavam taxas de óbitos de 100 e 110 óbitos/mês, respectivamente. Hoje, há equipes de abordagem em seis hospitais públicos e uma funerária da região.

A eficácia da equipe de abordagem pode ser demonstrada no questionário aplicado às famílias dos doadores de córnea do mês de maio de 2004 em que 63 (82,9\%) das 76 doações só foram efetivadas mediante a abordagem das equipes treinadas, enquanto apenas $13(17,1 \%)$ foram doações previamente requisitadas pelos próprios doadores.

O sistema de captação de órgãos, montado em 1990 na Espanha, baseado no treinamento de equipes de abordagem e no papel da mídia, foi responsável por um aumento de $75 \%$ no número de doações, passando de 14 para 25 doadores por mil habitantes ${ }^{(11)}$.

Spital constatou que nos Estados Unidos apenas 38\% de sua amostra tinham deixado claro para seus familiares da vontade de doação de órgãos ${ }^{(12)}$, enquanto Basu constatou que $37 \%$ dos entrevistados sobre doação de órgãos, em Toronto, haviam assinado previamente o cartão de doação ${ }^{(13)}$. Muraine e colaboradores atestaram que $17 \%$ dos doadores na França haviam discutido com familiares sobre doação de órgãos ${ }^{(14)}$.

Considerando-se que aproximadamente $1 \%$ da população 
de uma dada cidade vai a óbito em um ano, e que Sorocaba possui cerca de 500.000 habitantes, deveríamos ter uma taxa de captação só na cidade de Sorocaba de cerca de 5.000 doações em um ano ou de 416,66 doações/mês. Ou seja, apesar de os índices encontrados serem altos (185 doações em maio de 2004), eles estão aquém da quantidade desejada.

A Fundação Banco de Olhos de Goiás, instituto sem fins lucrativos, que representa o Banco de Olhos credenciado pelo sistema nacional de transplantes naquela região, trabalha com quatro equipes de abordagens dispostas no Instituto Médico Legal (IML) e no Serviço de Verificação de Óbitos (SVO). Há ainda uma pessoa em Catalão, interior de Goiás, e enfermeiros treinados pela Central de Transplantes de Goiás, alocados nos hospitais da capital, responsáveis pelo acionamento de uma das equipes de abordagens no caso de doação de tecidos oculares. As equipes de abordagens em Goiás estão instaladas desde de 1974. Antes delas, as doações oscilavam entre 5-15/mês, atualmente giram em torno de 115 a 125 doações de tecidos oculares por mês. As campanhas de doações realizadas com panfletagens e stands educativos em shoppings ocorrem uma vez por ano e são feitas em parceria com a Central de Transplantes de Goiás*.

O Banco de Olhos do Hospital das Clínicas da Faculdade de Medicina de Ribeirão Preto atua por busca ativa desde 1995 utilizando uma equipe de abordagem constituída de três funcionários, contratados pelo Hospital das Clínicas em períodos de $6 \mathrm{~h} /$ dia e $40 \mathrm{~h} / \mathrm{semana}$, com plantões a distância e horas extras pagas pela Fundação. A equipe atua em seis hospitais de grande porte: dois Hospitais das Clínicas (HCUSP), Hospital São Francisco, Hospital São Paulo, Beneficência Portuguesa e Hospital São Lucas, sendo a maior parte das doações provenientes dos dois HCs. O funcionário do controle de leitos do hospital comunica o óbito de algum paciente a um dos funcionários da equipe de abordagem que, então, entra em contato telefônico com um dos familiares e, no caso da aceitação de doação, leva o documento à casa da pessoa para assinar. Além dos hospitais, atuam ainda na funerária Campos Elíseos, no IML e no SVO. Tanto os funcionários da abordagem quanto o do controle de leitos recebem incentivos proporcionais ao êxito na busca ativa, além disso, a abordagem é feita em $100 \%$ dos óbitos de maiores de dois anos. Esta política de abordagem foi responsável pelo aumento progressivo do número de doações de 120 doações/ ano, até 1995, para $1.097 \mathrm{em} \mathrm{2004**.}$

O Banco de Olhos de São José do Rio Preto promove palestras em escolas e hospitais para divulgar a necessidade de doação de órgãos, além disso, há sempre a divulgação pela imprensa de nomes de pessoas famosas que doaram órgãos. O BOSJRP possui uma equipe de abordagem constituída de dois enfermeiros, que atuam no Hospital Universitário de São José do Rio Preto e são responsáveis por 99\% das doações obtidas. A equipe de abordagem começou a agir em 1997 com

\footnotetext{
* FBOG 2005. Comunicação verbal

** BOHCFMRP 2005. Comunicação verbal
}

uma pessoa e em 2003 com duas pessoas, sendo abordados apenas potenciais doadores entre 2 e 60 anos. Relatos de 1991 mostram apenas uma a duas doações/ano. Em 1997, com a contratação de um enfermeiro para a abordagem, foram 69 doações, em 1998, foram 128 até chegar em 2004 a 174 doações por ano $^{(15)}$.

Um dos alicerces do BOS é que toda pessoa deva ser considerada um doador em potencial, sem limites de idade, de tal forma que a divulgação da necessidade e importância da doação de órgãos transcorra mais facilmente, vencendo o medo do não-aproveitamento de um tecido doado pela população geral.

No que tange aos aspectos demográficos dos doadores, a idade média foi de $65,1 \pm 14,7$ anos e $50(65,8 \%)$ dos doadores tinham mais de 60 anos. Não houve doadores menores de 18 anos naquele mês. Na Espanha, apenas 20\% dos doadores atuais possuem mais de 60 anos $^{(11)}$. Na França, a idade média dos doadores é de 64,8 anos $^{(14)}$. Pottecher e colaboradores mostraram uma diminuição na recusa de doação à medida que a idade aumenta, de tal forma que a taxa de recusa chega a $34 \%$ quando o falecido é menor de 18 anos e a menos de $14 \%$ quando ele está acima dos 50 anos $^{(16)}$.

No presente estudo, $42(55,3 \%)$ doadores eram do sexo masculino, valor similar ao da literatura $(55 \%)^{(14)}$.

Dos 76 doadores de nossa amostra, 61 (80,3\%) eram católicos, enquanto $15(19,7 \%)$ eram evangélicos. Ainda que a maior parte da população brasileira seja católica, e que tal diferença possa ser atenuada por este fato, é necessária a realização de novas campanhas de educação em escolas e outros tipos de congregações religiosas para informação mais eficiente e conscientização da população sobre a importância da doação.

Razões religiosas ou culturais para negar o consentimento à doação, ainda que notáveis, são menos importantes na taxa de doação de córneas que deficiências na organização e motivação do Sistema de captação ${ }^{(17)}$. Diamond et al. não encontraram diferença estatisticamente significante entre grupos religiosos na obtenção de doações. Na sua pesquisa, em apenas três casos, o consentimento foi negado devido a razões reli$\operatorname{giosas}^{(4)}$. Burroughs et al. perceberam que as taxas de doações foram mais altas para indivíduos que acreditavam que vida após a morte não seria um problema para a doação ${ }^{(18)}$.

Neste estudo, o nível de escolaridade do familiar que assinou a doação foi responsável pelo entendimento do problema e maior adesão à prática de doação de órgãos.

A renda mensal baixa encontrada tanto no grupo dos doadores quanto no das pessoas que assinaram a doação deve-se ao fato de que todas as equipes de abordagens do BOS trabalham em hospitais públicos, devido ao maior volume de óbitos nestas instituições. Em um hospital particular da cidade, a equipe de enfermagem do próprio hospital é responsável pela abordagem da família dos potenciais doadores e posterior contato com a equipe do Banco de Olhos, entretanto, por motivos já discutidos em outros artigos, esta prática não é tão eficaz quanto a de uma equipe de abordagem 
treinada somente para este fim, uma vez que o médico ou enfermeiros atendentes podem não ser capazes de requerer a doação a familiares por medo de exposição da confiança neles depositada legalmente, por respeito ao luto da família ou por qualquer outra dificuldade em obter cooperação da equipe de transporte ${ }^{(19)}$.

Neste estudo percebeu-se que ter alguém na família com doença nos olhos ou com necessidade de transplante de córnea não foi fator preditivo positivo para a doação de córneas. Sessenta e quatro $(84,2 \%)$ dos doadores e $60(78,9 \%)$ das pessoas que assinaram o termo de doação não possuíam casos de necessidade de transplante na família, semelhante à quantidade encontrada na literatura ${ }^{(13)}$.

O papel da mídia na doação de órgãos aliado à credibilidade da instituição são mandatórios na conscientização da população. A profissionalização das equipes de abordagem requer intenso treinamento, entretanto, o resultado é logo percebido quando $82,9 \%$ das doações foram obtidas devido ao seu trabalho.

\section{ABSTRACT}

Penetrating keratoplasty has been the leading and the most successful type of transplant in the world, however corneal deficiency is a commom problem usually presented to corneal surgeons. Purpose: Impact evaluation of the number of corneal graft donations to the Sorocaba Eye Bank after the implementation of a corneal graft procurement system; to draw the socioeconomic profile of corneal graft donors of the Sorocaba Eye Bank (SEB). Methods: Retrospective study on donations to SEB from its creation and after the development of media marketing. Prospective analysis of the socioeconomic profile of corneal graft donors by a questionnaire sent as letters to the families of the donors in a certain month. Results: SEB began its work in 1971 by spreading need of organ donation through lectures in churches, shopping malls, community meetings, radio programs, television programs, etc. In the 70s, the number of retrieved corneal grafts was 1 or $2 /$ month. Between 1984 - 1989 a procurement coordination team was trained to act in mortuaries and by 2000 they also began to work in public hospitals. In 1984 only 260 corneal grafts were retrieved. This number has been increasing to 2,778 corneal graft donations in 2004. The questionnaire was answered by 76 of the 93 donor families, with a response rate of $81.7 \%$. Donor age had a mean of $65.1 \pm 14.7 \mathrm{y} / \mathrm{o}$, forty-two (55.3\%) were men. Educational level of the donor families was an important factor for organ donation, once $36.8 \%$ had concluded high school and $34.2 \%$ completed university. The great majority, sixty-three $(82.9 \%)$ of the corneal grafts were donated through the efforts of the procurement coordination team. Conclusion: The role of the media and institutional credibility are mandatory for public commitment to organ donation. The proficiency of the procurement coordination team requires intensive training, as the results show that $82.9 \%$ donations were made thanks to their efforts.

Keywords: Eye banks; Directed tissue donation; Tissue donors; Tissue and organ procurement/methods; Cornea; Social class; Marketing

\section{REFERÊNCIAS}

1. Sistema Nacional de Transplantes [sítio na Internet] Brasília (DF): Ministério da Saúde; 2005. [citado 2005 Jun 12]. Disponível em: dtr2001.saude.gov.br/ transplantes/integram.htm

2. Eye Bank Association of America. Eye Banking Activity: 1987. Washington, DC: Eye Bank Association of América; 1988.

3. Report of the organ transplant panel. Corneal transplantation. Council on Scientific Affairs. JAMA. 1988;259(5):719-22.

4. Diamond GA, Campion M, Mussoline JF, D’Amico RA. Obtaining consent for eye donation. Am J Ophthalmol. 1987;103(2):198-203.

5. United Kingdom Transplant Support Service Authority. Transplant activities. Bristol, UK: United Kingdom Transplant Support Service Authority; 1996.

6. Organizacion Nacional de Transplantes. Actividad de obtencion e implante de tejidos humanos. Madrid: Organizacion Nacional de Transplantes; 1996.

7. First MR. Transplantation in the nineties. Transplantation. 1992;53(1):1-11.

8. Delbosc B, Boissier F. [French Directory of Eye Banks. Report on activities during 1993-1997]. J Fr Ophtalmol. 1999;22(2):180-5. French.

9. Carrey I, Hudel Y, Salame N, Queguigner F, Maux R, Delbosc B. [Procurement of corneas: analysis of inventory of hospital coordination. Prospective study at the Besançon Hospital University during the course of one year]. J Fr Ophtalmol. 2000;23(10):996-1000. French.

10. Matesanz R, Miranda B. Organ donation - the role of the media and of public opinion. Nephrol Dial Transplant. 1996;11(11):2127-8.

11. Matesanz R, Miranda B, Felipe C, Naya MT. Continuous improvement in organ donation. The Spanish experience. Transplantation. 1996;61(7):1119-21.

12. Spital A. Mandated choice. A plan to increase public commitment to organ donation. JAMA. 1995; 273(6):504-6. Comment in: JAMA. 1995;274(12): 942-3.

13. Basu PK, Hazariwala KM, Chipman ML. Public attitudes toward donation of body parts, particularly the eye. Can J Ophthalmol. 1989;24(5):216-20.

14. Muraine M, Menguy E, Eupherte L, Martin J, Pouille P, Sadorge T, Brasseur G. Une étape importante du prélèvement de cornées: l'entretien avec la famille des donneurs. J Fr Ophtalmol 1997;20(1):25-30.

15. Pottecher T, Jacob F, Pain L, Simon S, Pivirotto ML. Information des familles de donneur d'organes. Facteurs d'acceptation ou de refus du don. Résultats d'une enquête multicentrique. Ann Fr Anesth Reanim. 1993; 12(5): 478-82.

16. Loewenstein A, Rahmiel R, Varssano D, Lazar M. Obtaining consent for eye donation. Isr J Med Sci. 1991;27(2):79-81.

17. Burroughs TE, Hong BA Kappel DF, Freedman BK. The stability of family decisions to consent or refuse organ donation: would you do it again? Psychosom Med. 1998;60(2):156-62.

18. Organ donor recruitment. Council on Scientific affairs. JAMA. 1981;246(19): 2157-8.

19. Morais M, Silva RCMA, Ramalho HJ, Silva RF, Abbud-Filho M. As Organizações de Procura de Órgãos (OPOS) são efetivas? Análise de sete anos de atividade de uma OPO brasileira. Arq Ciênc Saúde. 2004;11(4): 225-9. 